\title{
NON-PHARMACOLOGICAL THERAPY OF HYPERLIPIDAEMIA
}

\author{
Pathak U N ${ }^{1}$, Gurubacharya $\mathrm{D} \mathrm{L}^{1}$
}

\section{ABSTRACT}

Hyperlipidaemia is one of the major contributors to atherosclerosis and Coronary Heart Disease (CHD) in our society. Numerous clinical and epidemiological studies have shown repeatedly that an elevated blood cholesterol level is one of the major modifiable risk factors associated with the development of CHD. In particular, these studies have demonstrated that low- density lipoprotein (LDL) cholesterol is the primary lipoprotein mediating atherosclerosis. Non-pharmacological therapy especially dietary therapy and exercise remains the first line of treatment in hyperlipidaemia, with pharmacotherapy reserved for use in patients at high risk of coronary heart disease or patients who do not respond to non-pharmacological therapy.

Key Words: Hyperlipidaemia, LDL Cholesterol, HDL Cholesterol, coronary Heart Disease (CHD), Atherosclerosis, National Cholesterol Education Program (NCEP)

\section{INTRODUCTION}

Hyperlipidaemia, abnormal elevation of plasma cholesterol and/or triglyceride level, is one of the most common clinical problems that confront the physician in daily practices. Much attention has been focused on these disorders because there is a strong association of hyperlipidaemia - especially hypercholesterolemia- with development of atherosclerosis, and of hypertryglyceridaemia with pancreatitis $^{1}$. Epidemiologic, angiographic and postmortem studies have documented a causal relationship between elevated serum cholesterol levels and the genesis of coronary heart disease. Angiographic studies show that aggressive cholesterol reduction by a variety of methods, as

1. Nepal Medical College, Jorpati, Kathmandu, Nepal.

Address for correspondence : Dr. Urgra Narayan Pathak, Associate Professor

Dept. of Medicine

Nepal Medical College, Attarkhel, Jorpati

Kathmandu, Nepal. 
opposed to dietary modification alone, results in increased rates of plaque regression and stabalization $^{2}$. Numerous clinical and epidemiological studies have shown repeatedly that an elevated blood cholesterol level is one of the major modifiable risk factors associated with the development of Coronary Heart Disease. ${ }^{3}$ Approaches to management of hyperlipidaemia can be both non-pharmacological and pharmacological. Each approach complements the other. However non- pharmacological therapy should be viewed as basic therapy. The management of hyperlipidaemia aims to reduce the risk of Coronary Heart Disease.

\section{DIETS}

The goal of dietary therapy is to reduce elevated total cholesterol and LDL cholesterol levels to the target values while maintaining a nutritious diet. Dietary therapy should be initiated in patients who have borderline-high LDL cholesterol levels (130 to $159 \mathrm{mg} / \mathrm{dl}$ ) and two or more risk factors for CHD and in patients who have LDL levels of $160 \mathrm{mg} / \mathrm{dl}$ or greater. The objective of dietary therapy in primary prevention is to decrease the LDL cholesterol level to $160 \mathrm{mg} / \mathrm{dl}$ if only one risk factor for CHD is present and to less than $130 \mathrm{mg} / \mathrm{dl}$ if two or more risk factors are identified. In the presence of documented CHD, dietary therapy is indicated in the patients who have LDL values exceeding $100 \mathrm{mg} / \mathrm{dl}$, with the aim of lowering the LDL level to $100 \mathrm{mg} / \mathrm{dl}$ or less ${ }^{4}$. Clinical trials consistently report. that the lipid-lowering effects of dietary measures are greatest in persons with higher initial values of total cholesterol, LDL cholesterol and triglycerides. ${ }^{5,6,7}$

Step I and Step II diets are designed to progressively reduce intake of saturated fats, cholesterol and total calories to decrease lipoprotein values and promote weight loss in overweight persons ${ }^{5}$. When Step I diet is insuffient, and before the addition of medical therapy, Step II dietary management is mandatory.

\section{NCEP Dietary Guidelines ${ }^{5}$}

\begin{tabular}{|l|c|c|}
\hline \multicolumn{1}{|c|}{ Nutrient } & Step I diet & Step II diet \\
\hline Total fat & $<30 \%$ of calories & $<30 \%$ of calories \\
\hline Saturated fat & $<10 \%$ of calories & $<7 \%$ of calories \\
\hline Polyunsaturated fat & $<10 \%$ of calories & $<10 \%$ of calories \\
\hline Monounsaturated fat & $10-15 \%$ of calories & $10-15 \%$ of calories \\
\hline Cholesterol & $<300 \mathrm{mg} /$ day & $<200 \mathrm{mg} /$ day \\
\hline Carbohydrate & $50-60 \%$ of calories & $50-60 \%$ of calories \\
\hline
\end{tabular}

NCEP: National Cholesterol Education Program

The Step I diet has been shown to lower the total serum cholesterol level by 3 to 14 percent, while Step II diet may lower the total cholesterol level an additional 3 to 7 percent ${ }^{5}$. Not all studies, however have reported similar reductions. Hence, patients should be informed that even with strict adherence to the Step I diet, a Step II diet may be needed to effect significant improvement in the lipid profile. The NCEP recommends evaluating the patient's response to dietary therapy by monitoring the total cholesterol level after 6 weeks and 12 weeks of Step I diet. In primary prevention of CHD (that is, in patients without evidence of CHD), dietary therapy should be maintained for six months before drug therapy is initiated. In patients at risk of CHD or with a high total cholesterol or LDL values, drug therapy should be initiated at an early stage. In patients with CHD and an LDL cholesterol value above $100 \mathrm{mg} / \mathrm{dl}$, therapy should begin with Step II diet. 


\section{Dietary Guideline for a person with hyperlipidaemia}

\begin{tabular}{|c|c|}
\hline Food items to choose more often & Food items to choose less often \\
\hline $\begin{array}{l}\text { Breads and Cereals } \\
>6 \text { servings per day, adjusted to caloric needs } \\
\text { Breads, cereals, especially whole grains; pasta; rice; } \\
\text { potatoes; dry beans and peas; low fat crackers and } \\
\text { cookies. }\end{array}$ & $\begin{array}{l}\text { Breads and Cereals } \\
\text { Many bakery products, including } \\
\text { doughnuts, biscuits, butter rolls, muffins, croissants, sweet } \\
\text { rolls, Danish cakes,pies, coffee cakes, cookies }\end{array}$ \\
\hline $\begin{array}{l}\text { Vegetables } \\
\text { 3-5 servings per day fresh, frozen, or canned, without } \\
\text { added fat, sauce, or salt. }\end{array}$ & $\begin{array}{l}\text { Vegetables } \\
\text { Vegetables fried or prepared with butter, cheese, or } \\
\text { cream sauce }\end{array}$ \\
\hline $\begin{array}{l}\text { Fruits } \\
2-4 \text { servings per day fresh, frozen, canned, dried }\end{array}$ & $\begin{array}{l}\text { Fruits } \\
\text { Fruits fried or served with butter or cream }\end{array}$ \\
\hline $\begin{array}{l}\text { Dairy products } \\
2-3 \text { servings per day Fat- free milk, } \\
\text { buttermilk,yogurt,cottage cheese; fat free and low fat } \\
\text { cheese }\end{array}$ & $\begin{array}{l}\text { Dairy Products } \\
\text { Whole milk, whole milk yogurt, ice cream, cream, } \\
\text { cheese }\end{array}$ \\
\hline $\begin{array}{l}\text { Eggs, } \\
<2 \text { egg yolks per week } \\
\text { Egg whites or egg substitute }\end{array}$ & $\begin{array}{l}\text { Eggs } \\
\text { Egg yolks, whole eggs }\end{array}$ \\
\hline $\begin{array}{l}\text { Meat, poultry, Fish } \\
<5 \mathrm{oz} \text { per day } \\
\text { Lean cuts loin, leg, round; extra lean hamburger; cold } \\
\text { cuts made with lean meat or soy protein; skinless } \\
\text { poultry; fish }\end{array}$ & $\begin{array}{l}\text { Meat, Poultry, Fish } \\
\text { Higher fat meat cuts;ribs,regular hamburger, bacon, } \\
\text { sausage; cold cuts, liver, brains, fried meat, fried poultry, } \\
\text { fried fish }\end{array}$ \\
\hline $\begin{array}{l}\text { Fats and Oils } \\
\text { Amount adjusted to caloric level: } \\
\text { Unsaturated oils; soft or liquid margarines and } \\
\text { vegetables oil spreads, salad dressings, seeds, and nuts }\end{array}$ & $\begin{array}{l}\text { Fats and Oils } \\
\text { Butter, margarine,chocolate,coconut }\end{array}$ \\
\hline
\end{tabular}

\section{WEIGHT REDUCTION}

Obesity frequently elevates cholesterol level in both very-low-density lipoproteins (VLDL) and LDL fractions, raises triglyceride levels; lower HDL cholesterol levels, raises blood pressure and promotes glucose intolerance. Weight loss lowers total cholesterol and its LDL and VLDL fractions, lowers triglycerides and raises HDL cholesterol? Weight loss also lowers blood pressure and improves glycaemic control.

\section{EXERCISE}

Regular physical exercise can reduce VLDL levels, raise HDL cholesterol and, in some persons, lower LDL levels. Regular physical activity lowers blood pressure and reduces insulin resistance. ${ }^{5}$

Patients are more likely to comply with exercise programs that are tailored to meet individual goals,
Examples of Moderate ${ }^{1}$ Physical Activity in Healthy Adults ${ }^{2}$

- $\quad$ Brisk walking (3-4 mph) for 30-40 minutes

- $\quad$ Swimming-laps for 20 minutes

- $\quad$ Bicycling for pleasure or transportation, 5 miles in 30 minutes

- Volleyball (noncompetitive) for 45 minutes

- $\quad$ Raking leaves for 30 minutes

- Moderate lawn mowing (push a powered mower) for 30 minutes

- Home care - heavy cleaning

- Basketball for 15-20 minutes

- Golf - pulling a cart or carrying clubs

- $\quad$ Social dancing for 30 minutes

1. Moderate intensity defined as 4-7 kcal/minute or 3-6 METS. METS (work metabolic rate/resting metabolic rate) are multiples of the resting rates of oxygen consumption during physical activity. One MET represents the approximate rate of oxygen consumption of a seated adult at rest, or about $3.5 \mathrm{~mL}$ per min per $\mathrm{kg}$.

2. This table was adapted from the recommendations of the Surgeon General's Report on Physical Activity and Health (U.S. Department of Health and Human Services. Physical activity and health ... 1996b) and the Centers for Disease Control and Prevention and American College of Sports Medicine (Pate et al., 1995). 
interests and needs. Most patients benefit from aerobic exercise that target large muscle groups, performed for 30 minutes four or more times a week ${ }^{7}$. Shorter, but more frequent, aerobic exercise sessions provide similar benefits. Overweight patients should engage in low-intensity exercise more frequently and for longer duration.

\section{ALCOHOL INTAKE}

Alcohol exerts several effects on lipid levels, including raising the serum triglyceride and HDL cholesterol levels. Its effect on LDL cholesterol appears to be minimal. Since excessive alcohol causes numerous adverse effects, including hepatic toxicity, cardiomyopathy, motor vehicle crashes and extensive psychosocial consequences, it is not recommended for the prevention of $\mathrm{CHD}^{5}$.

\section{SMOKING}

Cigarette Smoking remains a cardiovascular risk factor. Cigarette smoking is associated with substantially lower levels of HDL cholesterol. Patients who stop smoking can expect an increase of up to 30 percent in their HDL levels ${ }^{8}$.

\section{DIETARY FIBER}

Soluble fiber has been shown to modestly reduce total cholesterol and LDL cholesterol levels 5 . Current dietary guidelines recommend a total daily fiber intake of at least 20 to $30 \mathrm{~g}$ for adults, with 25 percent of the fiber being soluble fiber ${ }^{5}$. These levels can be attained with the proposed six or more daily servings of grain products and five or more daily servings of fruits and vegetables. Adding $3 \mathrm{~g}$ per day of soluble fiber from oat bran can reduce total cholesterol by 5 to $6 \mathrm{gm}$ per $\mathrm{dl}^{7}$. Moreover, a high-carbohydrate, low-fiber diet typically raises serum triglyceride levels and lower HDL cholesterol levels. Conversely, a high-carbohydrate, high-fiber diet may lower the serum triglyceride level and raise HDL cholesterol level ${ }^{9}$. A high-fiber, low-fat diet also provides other beneficial effects, including improved glycaemic control, weight reduction and earlier satiety, prevention of diverticular disease and, possibly, prevention of colorectal cancer 9 . High intake of soluble fiber contributes to gastrointestinal side effects such as bloating and flatulence. Excessive intake of fiber may be associated with impaired absorption of important nutrients such as calcium. Supplementation with a daily multivitamin is therefore recommended for patients consuming a high-fiber diet and high-fiber supplements ${ }^{9}$.

\section{ANTIOXIDANTS}

Atherogenicity is promoted by oxidation and glycosylation of LDL cholesterol ${ }^{5}$. Several vitamins including vitamin $\mathrm{C}$, vitamin $\mathrm{E}$ and beta carotene, have antioxidant properties, which may provide protection against atherogenesis. Fruits and darkgreen and deep-yellow vegetables are rich sources of antioxidant vitamins.

\section{N-3 (OMEGA-3) POLYUNSATURATED FATTY ACIDS}

Omega-3 fatty acids, which are polyunsaturated fatty acids found in many fish, have been shown to reduce serum triglyceride concentrations ${ }^{10}$. This effect appears to be secondary to decreased VLDL production ${ }^{11}$. Generally omega-3 fatty acids have no effect on LDL cholesterol level, but large doses have been shown to reciprocally increase LDL cholesterol levels in person with hypertriglyceridemia ${ }^{12}$. The National Cholesterol Education Program (NCEP) guidelines do not recommend use of fish oils, although the consumption of fish is recommended in both Step I and Step II diets ${ }^{5}$. 


\section{GARLIC}

Herbal or botanical dietary supplements such as evening primrose, garlic, ginkgo, ginseng, grape extracts are available in health food stores, pharmacies, and many supermarkets. Several of the compounds have been promoted as agents to reduce the risk of CHD. Data from controlled trails regarding efficacy and safety are limited. In the case of garlic, a few randomized controlled studies are available, but the preponderance of available evidence fails to establish that garlic reduces LDL cholesterol levels ${ }^{13,14}$.

\section{AMLA (EMBLICA OFFICINALIS GAERTN)}

The experimental work done in albino rabbits has shown the beneficial effect of amla. Albino rabbits receiving amla has shown significant reduction in mean serum cholesterol level ${ }^{15}$. This study suggests that amla supplementation has cholesterol lowering effect. As amla is commonly used fruit in our society, it is advisable to take as supplementary to the medicine in the treatment of hyperlipidaemia.

\section{REFERENCES}

1. Witztum JL, Steinberg D. The hyperlipoproteinemias. In: Bennett JC, Plum F, eds. Cecil Textbook of Medicine: W.B. Saunders Company 1996: 1086.

2. Superko HR, Krauss RM. Coronary artery disease regression. Convincing evidence for the benefit of aggressive lipoprotein management. Circulation 1994; 90: 1056-69.

3. Levine GN, Keaney JF J r., Vita JA. Cholesterol reduction in cardiovascular disease. Clinical benefits and possible mechanisms. New Engl J Med 1995; 332: 512-21.

4. Ahmed SM, Clasen ME, Donnelly J E. Management of dyslipidemia in adults. Am Fam Physician 1998; 57: 2192-204, 2207-8.
5. National Cholesterol Education Program. Second report of the Expert Panel on Detection, Evaluation, and Treatment of High Blood Cholesterol in Adults (adult treatment panel II). Bethesda, Md: National cholesterol Education Program, National Institutes of Health, National Heart, Lung, and Blood Institute, 1993; DHSS publication no. (NIH) 93-3095: 5.

6. Yeshurun D, Gotto AM J r. Hyperlipidemia: perspectives in diagnosis and treatment. South Med J 1995; 88: 379-91.

7. Blake GH, Triplett LC. Management of hypercholesterolemia. Am Fam Physician 1995; 51: 1157-66.

8. Criqui $M H$, Wallace RB, Heiss $G$, Mishkel $M$, Schonfeld G, J ones GT. Cigarette smoking and plasma high-density lipoprotein cholesterol. The lipid Research Clinics Program Prevalence Study. Circulation 1980; 62: 70-6.

9. Anderson JW, Gustafson NJ. High- carbohydrate, high-fiber diet.Is it practicle and effective in treating hyperlipidemia? Postgrad Med 1987; 82: 403,47-50,55.

10. Roche HM, Gibney MJ . Effects of long-chain n-3 polyunsaturated fatty acids on fastinfg and postprandial triacylglycerol metabolism. Am J Clin Nutr 2000; 71: 232S-7S.

11. Harris WS. Fish oils and plasma lipid and liproprotein metabolism in humans: a critical review. J Lipid Res 1989; 30: 785-807.

12. Harris WS. N-3 fatty acids and serum lipoproteins: human studies. Am J Clin Nutr 1997; 65: 1645-54.

13. Gardner CD, Chatterjee LM, Carlson JJ . The effect of a garlic preparation on plasma lipid levels in moderately hypercholesterolemic adults. Atherosclerosis 2001; 154: 213-20.

14. Spigelski D, Jones PJ. Efficacy of garlic supplementation in lowering serum cholesterol levels. Nutr Rev 2001; 59: 235-41.

15. Mishra M, Pathak UN, Khan AB. Emblica officinalis Gaertn and serum cholesterol level in experimental rabbits. Brt J Exp Pathol 1981; 62: 526-8. 